\title{
Article \\ Sustainable Panels Made with Industrial and Agricultural Waste: Thermal and Environmental Critical Analysis of the Experimental Results
}

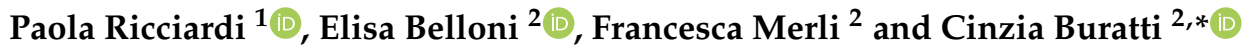 \\ 1 Department of Architecture and Civil Engineering, University of Pavia, Via Ferrata 1, 27100 Pavia, Italy; \\ paola.ricciardi@unipv.it \\ 2 Engineering Department, University of Perugia, Via G. Duranti 67, 06125 Perugia, Italy; \\ belloni.unipg@ciriaf.it (E.B.); merli@crbnet.it (F.M.) \\ * Correspondence: cinzia.buratti@unipg.it; Tel.: +39-075-5853993
}

\section{Citation: Ricciardi, P.; Belloni, E.;}

Merli, F.; Buratti, C. Sustainable

Panels Made with Industrial and Agricultural Waste: Thermal and Environmental Critical Analysis of the Experimental Results. Appl. Sci. 2021, 11, 494. https://doi.org/ 10.3390/app11020494

Received: 15 December 2020

Accepted: 2 January 2021

Published: 6 January 2021

Publisher's Note: MDPI stays neutral with regard to jurisdictional clai$\mathrm{ms}$ in published maps and institutional affiliations.

Copyright: $\odot 2021$ by the authors. Licensee MDPI, Basel, Switzerland. This article is an open access article distributed under the terms and conditions of the Creative Commons Attribution (CC BY) license (https:// creativecommons.org/licenses/by/ $4.0 /)$.

\begin{abstract}
Recycled waste materials obtained from industrial and agricultural processes are becoming promising thermal and acoustic insulating solutions in building applications; their use can play an important role in the environmental impact reduction. The aim of the present paper is the evaluation of the thermal performance of recycled waste panels consisting of cork scraps, rice husk, coffee chaff, and end-life granulated tires, glued in different weight ratios and pressed. Six panels obtained from the mixing of these waste materials were fabricated and analyzed. In particular, the scope is the selection of the best compromise solutions from the thermal and environmental points of view. To this aim, thermal resistances were measured in laboratory and a Life Cycle Assessment (LCA) analysis was carried out for each panel; a cross-comparative examination was performed in order to optimize their properties and find the best panels solutions to be assembled in the future. Life Cycle Analysis was carried out in terms of primary Embodied Energy and Greenhouse Gas Emissions, considering a "cradle-to-gate" approach. The obtained thermal conductivities varied in the 0.055 to $0.135 \mathrm{~W} / \mathrm{mK}$ range, in the same order of magnitude of many traditional systems. The best thermal results were obtained for the panels made of granulated cork, rice husk, and coffee chaff in this order. The rubber granulate showed higher values of the thermal conductivity (about $0.15 \mathrm{~W} / \mathrm{mK}$ ); a very interesting combined solution was the panel composed of cork (60\%), rice husk $(20 \%)$, and coffee chaff $(20 \%)$, with a thermal conductivity of $0.08 \mathrm{~W} / \mathrm{mK}$ and a Global Warming Potential of only $2.6 \mathrm{~kg} \mathrm{CO}$ eq $/ \mathrm{m}^{2}$. Considering the Embodied Energy (CED), the best solution is a panel composed of $56 \%$ of cork and $44 \%$ of coffee chaff (minimum CED and thermal conductivity).
\end{abstract}

Keywords: recycled waste materials; life cycle assessment; sustainability; thermal resistance measurements; buildings insulation

\section{Introduction}

Building and transport sectors are considered as main consuming sectors of global energy. The construction sector is responsible for one third of $\mathrm{CO}_{2}$ production [1]; in Europe, it accounts for the consumption of $40 \%$ energy [2], and for the emission of $36 \%$ of the total $\mathrm{CO}_{2}$. Nowadays, the technological solutions for the production of insulating materials often use a large amount of non-renewable natural resources, mainly based on glass fiber derived from silica sources, or other synthetic fibers derived from petroleum. One of the most significant challenges of the 21st century is to maintain sustainability in all levels of energy resources and environmental context [3]. The new Agenda for the Sustainable Development calls for less impacting technologies in all sectors of the human life; a circular economy strategy aims to maintain the value of a product by returning it into the product process at the end of its lifecycle, lowering material input, minimizing waste generation, and energy use. 
In this context, many non-conventional materials are emerging in construction components, especially the ones of natural origin, which are rare applications in the building sector.

Ecological insulation panels made of vegetable raw materials are increasingly used in the building sector; they have an interesting role because their use allows their revaluation as agricultural wastes, whose disposal is a serious issue [4], allowing them to be converted from waste to secondary raw material. In the construction industry, the goals of these materials are obtained thanks to the easy usability of raw materials, simplicity, applicability, low cost, as well as thermal and acoustic characteristics [5,6]. The last one in some cases is similar or a little bit worse than standard solutions, but they have a lower environmental impact as added value. Erkmen et al. [7] developed nature-friendly insulating materials designed from mixed natural substances: wool, kenaf, and wheat straw used as fibers, clay used as the filling material, and water-based paint binder used as the binder. The material with the best characteristics in terms of density $\left(0.45 \mathrm{~g} / \mathrm{cm}^{3}\right)$, thermal conductivity $(0.061 \mathrm{~W} / \mathrm{mK})$, and compressive strength $(4.9 \mathrm{MPa})$ was the one named $\mathrm{N} 2$, obtained by mixing clay (about $63 \%)$, wool (7\%), polyvinyl acetate $(10 \%)$, and water $(20 \%)$.

Volf et al. [8] tested some materials such as raw sheep wool, wood fiber, hemp, flax, and compressed straw bale in order to evaluate their thermal, hygrometric, and biological properties. From the test results it was observed that the thermal conductivity of the insulating materials based on natural fibers is $25 \%$ higher than mineral wool. In particular, flax and hemp fibers reached a very low thermal conductivity $(0.052 \mathrm{~W} / \mathrm{mK})$. Additionally, Cornaro et al. [9] developed a multi-sheet wall package, consisting of a straw bale layer and innovative natural plasters, giving a quantitative evaluation of the potential use of these materials in a sustainable building construction. Natural materials, such as straw bale and earth, have less embodied energy than processed materials and their use in buildings can give a valuable contribution to sustainability [10-12].

Bakatovich et al. [13] carried out an experimental campaign on panes prepared with rye straw, barley straw, wheat straw, oats straw, rice straw, flax boon, and rice husk. The possibility of using environmental friendly straw-flax boon plates for thermal insulation in cold climate was tested, also taking into account the reduction in carbon dioxide emissions into the atmosphere. The best thermophysical and mechanical performance was obtained for a composite structure of a material of different fibers with different size and shape, which allows to ensure the optimal structure of thermal insulating materials.

Furthermore, the possibility of using common construction and demolition waste materials in composite manufacturing is still under study in recent Literature [14-19].

Jian-Xin Lu et al. [15] focused on a green concrete partition wall block by using recycled glass as aggregates and incinerated sewage sludge ash (ISSA) as partial replacement for the cement. Based on these results, the applications of waste glass and ISSA for the construction of partition wall blocks resulted appealing as it not only provided an alternative approach to reuse the wastes, but also achieved good thermal performance (thermal conductivity lower than $1 \mathrm{~W} / \mathrm{mK}$ with the maximum percentage of glass content).

Another interesting study analyzes the powder residue from the production of clay bricks, slaked lime waste from acetylene production, and waste aluminum trimmings from workshops in order to compose very light bricks, achieving a thermal conductivity as low as $0.26 \mathrm{~W} / \mathrm{mK}[14]$.

In this context, the present paper presents the results in terms of thermal characterization and Life Cycle Analysis of innovative recycled waste materials obtained from cultivation discards and industrial production processes. In particular, building insulating panels composed of cork scraps (COR), end-life granulated tires (ELT), coffee chaff (CC), and rice husk ( $\mathrm{RH})$ in different weight ratios, glued together and pressed, were analyzed. They were separately studied in previous papers [12,16]: each waste material was used for the fabrication of a panel without mixing each other. In the present work, six different panels obtained by mixing the same waste materials were fabricated and analyzed; their thermal resistances were measured in laboratory and an LCA analysis was 
carried out. The novelty of this work is related to the analysis carried out, consisting in a cross-comparative study able to select the best compromise in terms of thermal performance and environmental impact.

\section{Materials and Testing Methods}

Samples made of several waste materials with different weight ratios were fabricated and characterized. Thermal and environmental performance is the main parameter studied in this first stage. It was investigated in order to establish the best mixing ratios. Another important characteristic is acoustic behavior, both in terms of sound absorption and noise insulation, studied for the panels composed of a single component in previous works [12,16]. The fire-resistance could be also a parameter to be evaluated in the future, such as the behavior of the panels in wet conditions; the authors measured water vapor permeability of some of the materials used for the mixing in this study, according to the International Standard EN ISO 12572 [20]. Data about hygrothermal properties of building materials are often lacking in the scientific literature, especially for innovative solutions. These aspects (acoustic, fire, and wet behavior of the panels) could be a future development of the work, once selected the best mixing solutions from a thermal and environmental point of view.

\subsection{Samples Manufacturing and Description}

The feedstock for the panels fabrication was supplied by several companies in Lombardy (Northern Italy) and Sardinia.

The cork was obtained from the extraction of the bark of the cork oak, which is processed through a grinding step in order to obtain different size of granules used for the fabrication of cork stoppers. It comes from a historical company from Sardinia (West Italy). Cork is very interesting from a sustainability perspective because it is related to many environmental issues, such as biodiversity conservation and wildfire prevention.

The rubber granulate used in this study comes from a big company located in the industrial area of Cherasco (Cuneo, Northern Italy). The company deals with the storage and shredding of the end-of-use tires from a wide area of Northern Italy; the shredding into microgranulates of different diameters (in the $0-4 \mathrm{~mm}$ range) allows an easy reuse of the rubber for different purposes: carpets, floors, conveyor belts, and so on. The outputs of the company depend on the final products: rubber chips (30-50 mm), granulate rubber $(0.8-20 \mathrm{~mm})$, powder rubber $(<0.8 \mathrm{~mm})$. Following the example of other European countries, the company would like to use these residues also as a component for the asphalt pavement. Therefore, the material has already a reuse aimed at respecting and protecting the environment, but it could also be used in the building sector, thanks to its interesting thermal insulation properties.

Rice husk is deriving from the paddy rice husking process, the rough rice (unpolished) after threshing. The percentage of rice husk over paddy rice depends on the variety and it can be in the $17 \%$ to $23 \%$ range by weight. Rice husk contains $75-90 \%$ of organic matter, such as cellulose, lignin, and mineral components in different amounts depending on rice variety, soil chemistry, climatic conditions, and even the geographic localization of the cultures [21,22].

The coffee chaff used in the composition came from an industry of Pavia (Northern Italy); it is the waste of the roasting process of the part that still remains attached to the green coffee beans after the purification and thresh processes [12].

All the tested samples were made in laboratory, in the form of square panels of $300 \times 300 \mathrm{~mm}^{2}$ for thermal tests (Figure 1). For the fabrication of these samples, it was used a cold-water-based polyurethane glue, with a density of $1.000 \mathrm{~kg} / \mathrm{m}^{3}$ and a percentage of $2.5 \%$ of the total weight. The choice of the weight ratio of the glue derived from many attempts that arose in previous works $[12,16]$. It is the minimum percentage able to bind the loose materials and to provide the samples with a good overall consistency. The used polyurethane-based glue was a polyurethane adhesive in aqueous dispersion: this adhesive 
was found to be easily applied by spray technique and made it possible to achieve the desired results with low doses. The pressing operation was carried out by means of a coldpress system specifically developed for this application: a load of 250-300 kg was applied to each sample and an anti-adhesive spray was previously applied to the surface, in order to simplify the removal of the sample from the formwork. Finally, two support panels of plasterboard (each $6 \mathrm{~mm}$-thick), one for each side of the recycled waste material, were used in order to have self-bearing specimens during the thermal measurements. Their total thicknesses vary in the 51 to $55 \mathrm{~mm}$ range, considering the contribution of plasterboard panels; a mean value was considered for each sample (see Figure 1d). The main features of the loose materials are reported in Table 1. Starting from the results obtained in the first survey campaigns $[12,16]$, it was possible to find the new compositions of the panels. The granulated cork is the material with the best conductivity properties, so that its weight ratio was fixed always higher than the other three. The analyses carried out in the present paper both in terms of thermal and environmental performance will allow to select the optimal mixing percentages by means of a cross comparative analysis. Therefore, the first three panels $(1,2$, and 3 ) are all made up of $70 \%$ cork (the material with the best performance according to previous studies [12,16]) and 30\% of the other materials. The fourth and fifth panels consisted of three kinds of loose material (40-30-30\%), and, finally, the last one contained all the scrap wastes (40\% of COR, $20 \%$ of CC, $20 \%$ of RH and $20 \%$ of ELT). Tables 2 and 3 show the characteristics of the examined composed panels.

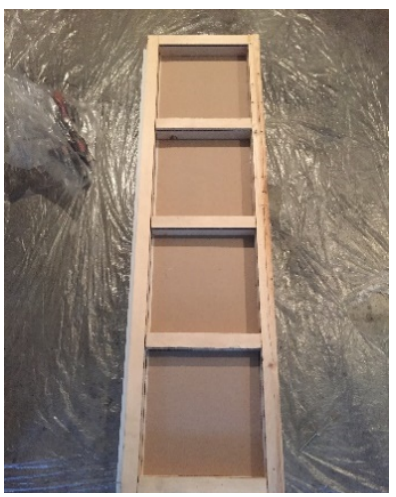

(a)

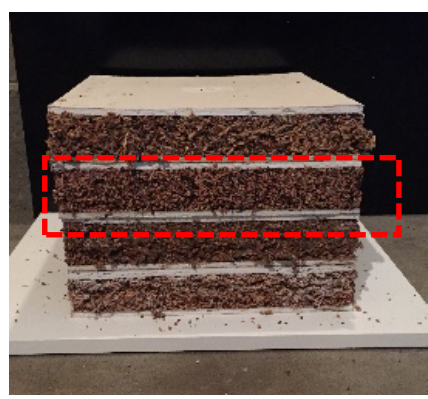

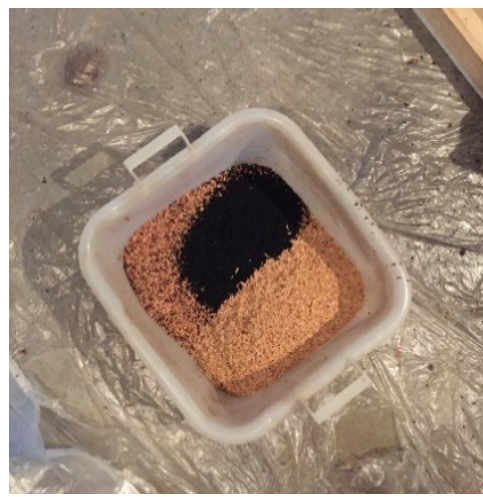

(b)

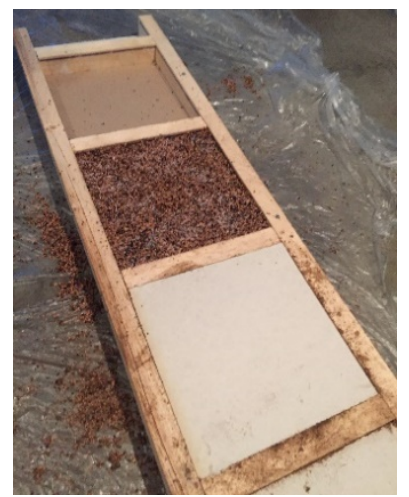

(c)

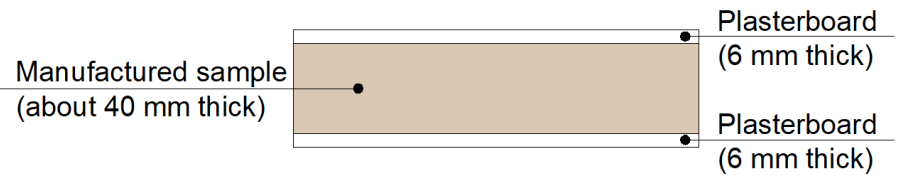

(d)

Figure 1. Different steps for the manufacturing of the samples: (a) formworks for the samples; (b) mixing phase of the loose materials; (c) positioning of the materials with glue in the formworks; (d) final panels and schematic section of a single sample. 
Table 1. Main characteristics of the loose materials $[12,16]$.

\begin{tabular}{ccccc}
\hline & Density $\left(\mathbf{k g} / \mathbf{m}^{\mathbf{3}}\right)$ & $\begin{array}{c}\text { Granule Size } \\
(\mathbf{m m})\end{array}$ & $\begin{array}{c}\text { Fire Reaction } \\
\text { Class }\end{array}$ & Calorific Value (kJ/kg) \\
\hline COR & 130 & $8-10$ & B2 & 17.000 \\
ELT & 600 & $1-2.5$ & B2 & 42.000 \\
RH & 170 & $1-9$ & A1 & 14.000 \\
CC & 78 & $<0.5$ & - & - \\
\hline
\end{tabular}

Table 2. Weight ratio of the manufactured samples.

\begin{tabular}{|c|c|c|c|c|c|c|}
\hline \multirow{2}{*}{\multicolumn{2}{|c|}{ Description of the Panels }} & \multirow{3}{*}{$\begin{array}{c}\text { Thickness (mm) } \\
52.7\end{array}$} & \multicolumn{4}{|c|}{ Weight Ratio (\%) } \\
\hline & & & \multirow{2}{*}{$\begin{array}{c}\text { COR } \\
70\end{array}$} & \multirow[t]{2}{*}{ ELT } & \multirow{2}{*}{$\begin{array}{c}\text { RH } \\
30\end{array}$} & \multirow[t]{2}{*}{$\mathrm{CC}$} \\
\hline 1 & $\mathrm{COR}+\mathrm{RH}$ & & & & & \\
\hline 2 & $\mathrm{COR}+\mathrm{CC}$ & 55.5 & 70 & & & 30 \\
\hline 3 & $\mathrm{COR}+\mathrm{ELT}$ & 52.3 & 70 & 30 & & \\
\hline 4 & $\mathrm{COR}+\mathrm{ELT}+\mathrm{RH}$ & 51.0 & 40 & 30 & 30 & \\
\hline 5 & $\mathrm{COR}+\mathrm{CC}+\mathrm{RH}$ & 51.5 & 40 & & 30 & 30 \\
\hline 6 & $\mathrm{COR}+\mathrm{ELT}+\mathrm{RH}+\mathrm{CC}$ & 52.3 & 40 & 20 & 20 & 20 \\
\hline
\end{tabular}

Table 3. Weights and densities of the manufactured samples.

\begin{tabular}{|c|c|c|c|c|c|c|c|}
\hline \multirow{2}{*}{\multicolumn{2}{|c|}{ Description of the Panels }} & \multicolumn{5}{|c|}{$\begin{array}{c}\text { Quantities of the Material in the } \\
\text { Mixtures (g) }\end{array}$} & \multirow[t]{2}{*}{$\begin{array}{l}\text { Density of the } \\
\text { Panels }\left(\mathrm{kg} / \mathrm{m}^{3}\right)\end{array}$} \\
\hline & & Glue & COR & ELT & RH & $\mathrm{CC}$ & \\
\hline 1 & $\mathrm{COR}+\mathrm{RH}$ & 363 & 335 & & 143 & & 177.5 \\
\hline 2 & $\mathrm{COR}+\mathrm{CC}$ & 579 & 437 & & & 187 & 240.8 \\
\hline 3 & $\mathrm{COR}+\mathrm{ELT}$ & 371 & 428 & 184 & & & 208.8 \\
\hline 4 & $\mathrm{COR}+\mathrm{ELT}+\mathrm{RH}$ & 372 & 252 & 189 & 189 & & 218.4 \\
\hline 5 & $\mathrm{COR}+\mathrm{CC}+\mathrm{RH}$ & 741 & 257 & & 193 & 193 & 298.4 \\
\hline 6 & $\mathrm{COR}+\mathrm{ELT}+\mathrm{RH}+\mathrm{CC}$ & 777 & 283 & 141 & 141 & 141 & 315.3 \\
\hline
\end{tabular}

\subsection{Thermal Characterization}

The apparatus named Small Hot-Box was used for thermal tests [23] (Figure 2); it was developed and calibrated by several preliminary measurements at the University of Perugia (Laboratory of Environmental Control, Department of Engineering), following some of the prescriptions of EN ISO 8990 [24]. A detailed description of the apparatus can be found in [9]. The thermal flux meter methodology is followed and the thermal conductivity is calculated considering the mean surface temperatures of the hot and cold sides $\left(T_{S H}\right.$ and $T_{S C}$, respectively), the heat flux through the sample $(q)$, and the total thickness of the specimen $(s)$, as reported in (1):

$$
\lambda=\frac{q}{T_{s H}-T_{s C}} \cdot s_{\text {sample }}\left[\frac{\mathrm{W}}{\mathrm{mK}}\right]
$$

The panels not being self-bearing, it was necessary to use support layers (support layer 1 and support layer 2), especially for the more fragile materials: in these cases it was calculated the thermal contribution of only one layer $\left(R_{\text {sample }}\right)$ from the total thermal resistance of the composed samples $\left(R_{t o t}\right)$, as reported in Equation (2):

$$
R_{\text {tot }}=R_{\text {support } 1}+R_{\text {sample }}+R_{\text {support } 2}=\frac{s_{\text {support } 1}}{\lambda_{\text {support } 1}}+\frac{s_{\text {sample }}}{\lambda_{\text {sample }}}+\frac{s_{\text {support } 2}}{\lambda_{\text {support } 2}} \quad\left[\frac{\mathrm{m}^{2} \mathrm{~K}}{\mathrm{~W}}\right]
$$

where:

- $R_{\text {support } 1}, s_{\text {support } 1}$, and $\lambda_{\text {support } 1}$ are, respectively, the thermal resistance $\left(\mathrm{m}^{2} \mathrm{~K} / \mathrm{W}\right)$, the thickness $(\mathrm{m})$, and the thermal conductivity $(\mathrm{W} / \mathrm{mK})$ of the first support panel; 
- $\quad R_{\text {support } 2}, s_{\text {support } 2, \text { and }} \lambda_{\text {support } 2}$ are, respectively, the thermal resistance $\left(\mathrm{m}^{2} \mathrm{~K} / \mathrm{W}\right)$, the thickness $(\mathrm{m})$, and the thermal conductivity $(\mathrm{W} / \mathrm{mK})$ of the second support panel;

- $R_{\text {sample }}, s_{\text {sample, }}$ and $\lambda_{\text {sample }}$ are, respectively, the thermal resistance $\left(\mathrm{m}^{2} \mathrm{~K} / \mathrm{W}\right)$, the thickness $(\mathrm{m})$, and the thermal conductivity $(\mathrm{W} / \mathrm{mK})$ of the sample layer to be tested.

Thermal properties of the support panels $\left(\lambda_{\text {support } 1}\right.$ and $\left.\lambda_{\text {support } 2}\right)$ were measured in a laboratory following the same procedure.

In order to evaluate the thermal conductivities of the samples, two tests were carried out for each sample; the first test was carried out considering a temperature inside the box equal to $45^{\circ} \mathrm{C}$, the second one has set-up temperature of $50{ }^{\circ} \mathrm{C}$. Both the measurements lasted for $2 \mathrm{~h}$ and in both cases the difference between the air temperature into the box and the air temperature in the room (hot and cold sides, respectively) was about or more than $20{ }^{\circ} \mathrm{C}$. The thermal resistances $R_{\text {support } 1}$ and $R_{\text {support } 2}$ were separately measured for each support. Considering equal to $\pm 5 \%$ the precision of the thermal flux meter and $\pm 0.10{ }^{\circ} \mathrm{C}$ the one of the thermoresistances, the measurement accuracy is $4-6 \%$ for all the tests. The relative uncertainties (type B) related to the fluctuation of the measured quantities during the test were also calculated, in compliance with International Stadard JCGM 100:2008 [25].

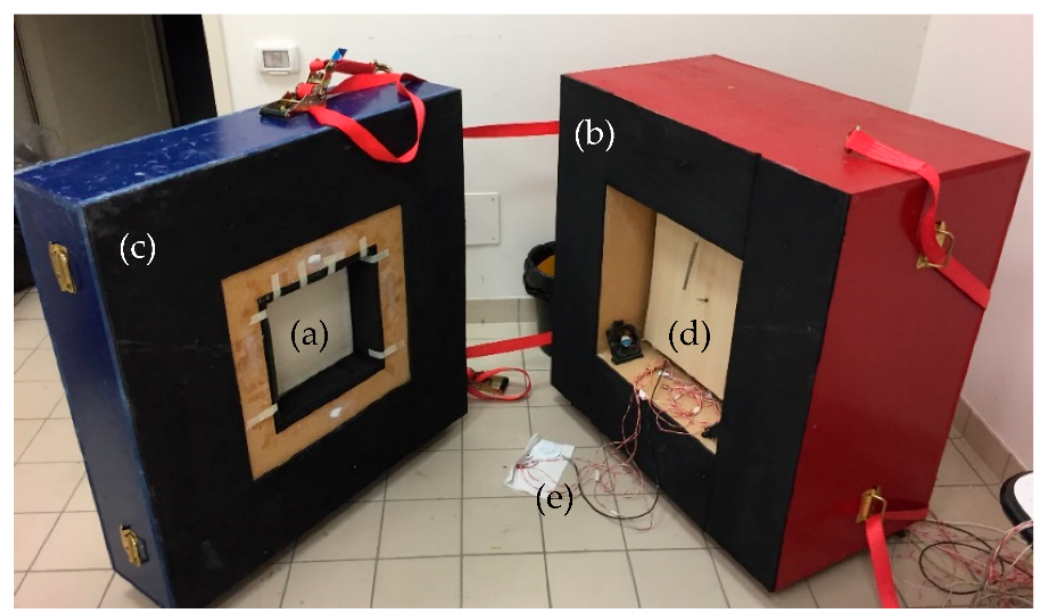

Figure 2. The Small Hot Box apparatus: a picture with a sample (a) installed inside; hot chamber (b); sample holder compartment (c); radiant shield of the heating system (d); thermoresistances and thermal flux meter probes (e).

\subsection{LCA Analysis: Methodology and Input Data}

Life Cycle Assessment (LCA) is a method for the evaluation of the products impact on the environment over the entire lifespan. The LCA method analyzes the resources extracted and quantifies the emissions related to a product [26]. It provides valuable information that allows managers to make decisions aimed at improving the environmental performance of their products. The methodology for the life cycle assessment analysis is given in the international standard ISO 14040-series [27,28]. LCA is organized in several steps:

- the goal and scope definition;

- the inventory analysis;

- the impact assessment analysis;

- the interpretation phases.

The collection of input data necessary for the calculation of the environmental impact is very important and it strongly influences the final result. Data could be taken from relevant studies, public databases of the employed LCA software, scientific publications, and from the companies information. Primary data, collected in the process chain of a product, are the most useful, allowing a more reliable evaluation. In the Life Cycle Inventory, data sources included foreground information, in which primary data were collected 
from the manufacturer of the panel and their components, background data, in which secondary data were taken from international Literature, and databases and tertiary data, from estimate models.

The selected materials were chosen considering their really available amounts and in these cases where the manufacturing systems have a lot of scraps that could be used. All the considered wastes, cork, coffee chaff, rice husk, and granulated tires, can be used for other applications such as additives in road pavements, concrete, and so on, or in energy conversion systems. An LCA analysis taking into account all the possible uses of the wastes could be helpful in choosing the best recycling process, considering other functional units. Moreover, this paper would like to focus on their application as based materials for insulation panels and to compare them each other.

In the present study, among the most important parameters, the cumulative energy demand (CED, MJ $/ \mathrm{kg}$ ), i.e., the energy consumed for the products manufacturing, and the global warming potential (GWP 100 years, $\mathrm{kg}$ of $\mathrm{CO}_{2 \mathrm{eq}}$ ) were calculated as environmental impact indexes associated to the panel production. The global warming potential (GWP) quantifies the carbon footprint, basing on a relative scale which compares the specific Green House Gas (GHG) emissions with an equivalent mass of $\mathrm{CO}_{2}$, whose GWP is equal to 1. IPCC 100-years Global Warming Potential (GWP) characterization factors were applied to convert greenhouse gas emissions into carbon dioxide equivalent $\left(\mathrm{CO}_{2 \mathrm{eq}}\right)$ emissions; the characterization factors used were 1, 25, and 298 for carbon dioxide, methane, and nitrous oxide $\mathrm{N}_{2} \mathrm{O}$, respectively. In particular the nitrogen oxides $\left(\mathrm{NO}_{X}\right)$ are relevant to greenhouse effect, due to their catalytic role in the production of tropospheric ozone. In general, the global warming potential is estimated as 30-33 and 7-10 for the time horizons of 20 and 100 years, respectively, comparable to that of methane. Anthropogenic induced $\mathrm{NO}_{\mathrm{x}}$ emissions enhance greenhouse effect and stratospheric ozone depletion in the time scale of more than a century [29].

The LCA analysis was performed by using SimaPro 8 [30] and the functional unit (f.u.) was defined in compliance with ISO standards 14040 series $[27,28]$. Then $1 \mathrm{~m}^{2}$ of manufactured panel was used as f.u., but another functional unit was considered, in order to assess the life cycle of the panel from thermal point of view and to perform the comparison with other waste recycled panels. In particular, the mass (in $\mathrm{kg}$ ) of insulating panel that involves a thermal resistance R equal to $1 \mathrm{~m}^{2} \mathrm{~K} / \mathrm{W}$, according to a proposal of the Council for European Producers of Materials for Construction [31] was used:

$$
\text { f.u. }=R \times \lambda \times \rho \times A \quad[k g]
$$

where $R$ is the thermal resistance equal to $1 \mathrm{~m}^{2} \mathrm{~K} / \mathrm{W} ; \lambda$ is the thermal conductivity of the panel in $\mathrm{W} / \mathrm{mK} ; \rho$ is the density of the panel in $\mathrm{kg} / \mathrm{m}^{3}$, and $A$ is the surface area, equal to $1 \mathrm{~m}^{2}$.

The system boundaries were fixed considering a "cradle to gate" approach; the production of the raw materials such as cork, end-life granulated tires, rice husk, and coffee chaff do not produce any impact to the whole life cycle of the panels, because they are byproducts of a different production chain and no energy consumptions are necessary to their reuse. On the contrary, they represent an allocation of waste, that in other scenarios could be disposed in landfill, resulting in an avoided waste.

As concerning installation, maintenance, and end-of-life, the impacts were neglected because no data were available, being the investigated materials at a prototype stage. The system boundaries and the general flow chart of the analysis are shown in Figure 3. 


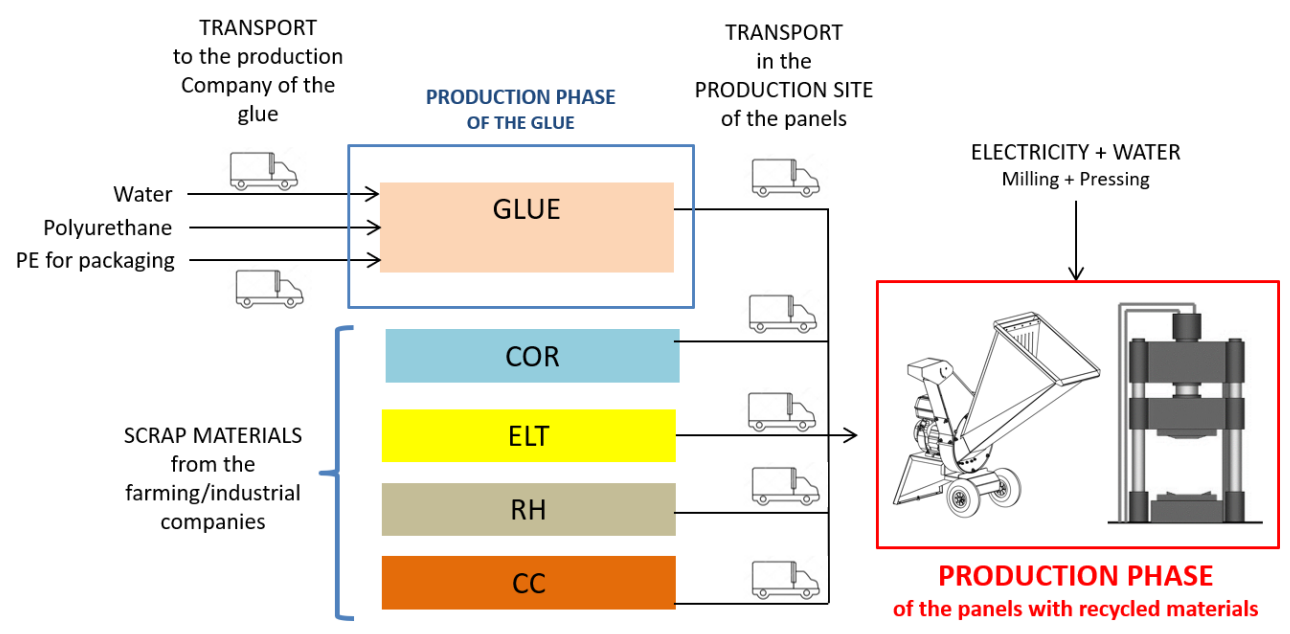

Figure 3. Flow chart of the LCA analysis from the cradle to the gate.

Three stages of the life cycle were considered: panel components supplying, transportation in all stages, and panel production. The panel production company is assumed to be in the North of Italy, in a barycentric position within the material sources (within a $20-30 \mathrm{~km}$ radius). The manufacturers of rice husk are located at an average distance of $160 \mathrm{~km}$ from the company, because the rice production is concentrated in Piemonte and Lombardia regions. The cork company is located in Sardinia and for this material the impact due to the transports are expected to be the highest. The glue manufacturer is at a mean distance of $300 \mathrm{~km}$ from the fabrication site of the panels. The transport impacts were evaluated thanks to general data provided by the Ecoinvent databases.

\section{Results and Discussion}

\subsection{Thermal Measurements}

In Table 4 the main data related to the thermal conductivity measurements are reported. Tests are all related to a hot side set-up temperature of $45{ }^{\circ} \mathrm{C}$ because tests at $50{ }^{\circ} \mathrm{C}$ showed higher uncertainties. A preliminary test was carried out in order to measure the thermal conductivity of the only plaster board support, found equal to $0.21 \mathrm{~W} / \mathrm{mK}$ (total thickness of the board equal to $12 \mathrm{~mm}$ ). After determining the total thermal resistances of the composed samples (plasterboard support, waste glued panel, and plasterboard support), the thermal resistance and the thermal conductivity of the only insulating panel were calculated, as shown in Equation (2). Table 4 shows data obtained for each test and the final value of the recycled insulating panels thermal conductivity.

Table 4. Thermal conductivity of the recycled mixed panels and related measured parameters.

\begin{tabular}{lcccccccc}
\hline \multirow{2}{*}{ Description of the Panels } & $\mathbf{s}_{\text {tot }}$ & $\mathbf{\Delta} \mathbf{T}_{\mathbf{a}}$ & $\mathbf{q}$ & $\mathbf{T}_{\mathbf{s , a v e r a g e}}$ & $\mathbf{R}_{\text {tot }}$ & $\dot{\boldsymbol{u}(\mathbf{R})}$ & $\boldsymbol{\lambda}_{\text {waste panel }}$ \\
\cline { 3 - 8 } & & $\mathbf{( m m )}$ & $\left.\mathbf{(}{ }^{\circ} \mathbf{C}\right)$ & $\mathbf{( W / \mathbf { m } ^ { 2 } )}$ & $\left.\mathbf{(}^{\circ} \mathbf{C}\right)$ & $\left.\mathbf{( m}^{\mathbf{2}} \mathbf{K} / \mathbf{W}\right)$ & $\mathbf{( \% )}$ & $\mathbf{( W / m K )}$ \\
\hline 0 & Plasterboard support & 6.0 & 20.3 & 77.0 & 29.6 & 0.03 & 5.6 & 0.210 \\
1 & COR + RH & 52.7 & 20.6 & 21.4 & 33.3 & 0.76 & 4.7 & 0.057 \\
2 & COR + CC & 55.5 & 20.1 & 21.7 & 33.5 & 0.74 & 4.1 & 0.064 \\
3 & COR + ELT & 52.3 & 19.4 & 24.5 & 33.7 & 0.62 & 5.7 & 0.071 \\
4 & COR + ELT +RH & 50.9 & 20.9 & 24.0 & 33.3 & 0.66 & 4.8 & 0.064 \\
5 & COR + CC + RH & 51.5 & 21.2 & 25.9 & 33.1 & 0.63 & 4.6 & 0.070 \\
6 & COR + ELT + RH + CC & 52.3 & 21.7 & 26.4 & 32.8 & 0.62 & 4.9 & 0.071 \\
\hline
\end{tabular}

These values should be analyzed considering the thermal conductivity of the wastebased panels composed of only one single material: the $\lambda$-values were measured by means of the same methodology in previous works [12,16] and they are resumed in Table 5. 
Table 5. Thermal conductivity of the recycled panels with a sole material and related measurement parameters $[12,16]$.

\begin{tabular}{cccccc}
\hline \multirow{2}{*}{ Panels Description } & $\boldsymbol{\Delta} \mathbf{T}_{\mathbf{a}}$ & $\mathbf{q}$ & $\mathbf{T}_{\mathbf{s}, \text { average }}$ & $\mathbf{R}_{\text {tot }}$ & $\boldsymbol{\lambda}_{\text {waste panel }}$ \\
\cline { 2 - 6 } & $\left.\mathbf{(}^{\circ} \mathbf{C}\right)$ & $\mathbf{( W / \mathbf { m } ^ { \mathbf { 2 } } )}$ & $\left.\mathbf{(}^{\circ} \mathbf{C}\right)$ & $\left.\mathbf{( m}^{\mathbf{2}} \mathbf{K} / \mathbf{W}\right)$ & $\mathbf{( W / m K )}$ \\
\hline COR & 21.2 & 14.5 & 34.7 & 0.83 & 0.055 \\
ELT & 20.9 & 30.4 & 36.4 & 0.30 & 0.135 \\
RH & 20.6 & 20.0 & 35.8 & 0.58 & 0.070 \\
CC & 20.4 & 24.0 & 36.4 & 0.39 & 0.076 \\
\hline
\end{tabular}

It is possible to observe that the best solution from the thermal point of view is obtained for the panel type 1, composed of $70 \%$ of cork and $30 \%$ of rice husk, which are the materials with the lowest thermal conductivity values (Table 5). Panels type 3 , 5 , and 6 have the same thermal insulation behavior $(0.07 \mathrm{~W} / \mathrm{mK})$, showing the worst performance, whereas intermediate values were found for samples 2 and $4(0.064 \mathrm{~W} / \mathrm{mK})$. All the measurements showed uncertainty u-values in the $4-5 \%$ range, except for panel 3 (cork and end-life granulated tires), with a slightly higher value $(5.7 \%)$, due to a higher variation of the heat flux during the test (differences of about $4.5 \mathrm{~W} / \mathrm{m}^{2}$ ): this is probably due to the configuration of the panel 3 , that is not very compact and regular in shape.

\subsection{Life Cycle Assessment: Main Results}

The LCA results in terms of carbon footprint and cumulative energy demand obtained for the panels composed of a single loose material are reported in previous works $[12,16]$ and they are summarized in Table 6, whereas the results related to the composed panels investigated in the present paper are reported in Table 7.

Table 6. GWP ( $\mathrm{kg} \mathrm{CO}_{2 \text { eq }}$ ) and CED (MJ) for $1 \mathrm{~m}^{2}$ of panel and for $\mathrm{R}=1 \mathrm{~m}^{2} \mathrm{~K} / \mathrm{W}[12,16]$.

\begin{tabular}{|c|c|c|c|c|}
\hline & GWP $\left(1 \mathrm{~m}^{2}\right)$ & GWP (1 R) & $\operatorname{CED}\left(1 \mathrm{~m}^{2}\right)$ & CED (1 R) \\
\hline & $\mathrm{kgCO} \mathrm{CO}_{2 \mathrm{eq}} 1 \mathrm{~m}^{2}$ & kg CO $\mathrm{Cq}_{2}$ f.u.(R) & $\mathrm{MJ} / 1 \mathrm{~m}^{2}$ & MJ/f.u.(R) \\
\hline COR & 3.07 & 3.687 & 61.85 & 76.99 \\
\hline ELT & 3.61 & 11.85 & 67.74 & 237.22 \\
\hline $\mathrm{RH}$ & 1.11 & 1.881 & 22.13 & 39.17 \\
\hline $\mathrm{CC}$ & 0.57 & 3.07 & 1.47 & 29.53 \\
\hline
\end{tabular}

Table 7. GWP ( $\mathrm{kg} \mathrm{CO} \mathrm{CO}_{2}$ ) and CED (MJ) for $1 \mathrm{~m}^{2}$ of panel and for thermal comparison (for $\mathrm{R}=1 \mathrm{~m}^{2} \mathrm{~K} / \mathrm{W}$ ); in bold the best environmental performance, in italic the worst one.

\begin{tabular}{|c|c|c|c|c|}
\hline & GWP $\left(1 \mathrm{~m}^{2}\right)$ & GWP (1 R) & $\operatorname{CED}\left(1 \mathrm{~m}^{2}\right)$ & CED (1 R) \\
\hline & $\mathrm{Kg} \mathrm{CO}_{2 \mathrm{eq}} / 1 \mathrm{~m}^{2}$ & $\mathrm{Kg} \mathrm{CO}_{2 \text { eq/f.u.(R) }}$ & $\mathrm{MJ} / 1 \mathrm{~m}^{2}$ & MJ/f.u.(R) \\
\hline 1 & 2.78 & 3.45 & 50.23 & 65.94 \\
\hline 2 & 2.62 & 3.60 & 45.10 & 63.05 \\
\hline 3 & 3.33 & 6.44 & 63.92 & 125.29 \\
\hline 4 & 2.74 & 5.90 & 52.00 & 113.95 \\
\hline 5 & 1.83 & 2.05 & 32.12 & 33.75 \\
\hline 6 & 2.65 & 5.14 & 43.31 & 92.24 \\
\hline
\end{tabular}

The best behavior is observed for Rice Husk and Coffee Chaff, both in terms of minimum Global Warming Potential and Cumulative Energy Demand, when compared to Cork and Granulated Tires, especially considering the thermal analysis (RH and CC have lower thermal conductivities in comparison to ELT, about $0.07 \mathrm{~W} / \mathrm{mK}$ ). COR could be very performant, but the contribution of the transports (from Sardinia to Northern Italy) influences the values of the embodied energy of the final product, despite the best thermal resistance. As expected, the results of the mixed panels are not very different from 
each other, especially in terms of GWP. Larger differences are observed in terms of CED, despite the results are aligned with the impacts of the previous analyzed panels.

In this second analysis, the influence of COR, which is the only one faraway supplied raw material, is not so significant, because it is present in all the mixing compositions of the 6 types of panels. The best performance is found for panel 5, composed of $40 \%$ COR, $30 \% \mathrm{CC}, 30 \% \mathrm{RH}$, whereas the worst one, not only in terms of thermal resistance but also in the environmental analysis, is panel 3, only composed of COR and ELT (CED (1R) 70\% higher than the one for panel 5).

\subsection{Discussion}

In order to optimize the final mixing of the experimental panels, a cross-comparative analysis was performed taking into account both the aspects (thermal performance and environmental impacts). This multivariate analysis was carried out for each type of panel: the thermal conductivity values $(\lambda)$ and the Global Warming Potential (GWP) were shown by the percentage change of the loose materials in the final composition of the panel. The analysis is also useful in order to find, for each type of panel, the best mixture able to ensure the best thermal and environmental performance (Figure 4). For panels types 4, 5, and 6 , composed of 3 or more waste materials, the percentage of Cork was considered and the complementary one was equally divided among the other two or three raw materials.

For panel 1 the best possible compromise between thermal and environmental performance is $37 \%$ of Cork and $67 \%$ of Rice Husk ( $\lambda$-value equal to $0.063 \mathrm{~W} / \mathrm{mK}$ and GWP $2.17 \mathrm{~kg} \mathrm{CO}$ eq $_{\text {eq }} / 1 \mathrm{~m}^{2}$ ), whereas for panel $250 \%$ of Cork and $50 \%$ of Coffee Chaff is a good mixing solution. In general, the composition chosen for panel 3 does not represent a good insulating solution and also the environmental properties are not advantageous. The best solution, in this case, is represented by the only Cork in the mixture. For panel 4, the best compromise is the mixture composed of $30 \%$ of Cork, $35 \%$ of Rice Husk and $35 \%$ of Rubber, with a thermal conductivity that is not much higher than $0.07 \mathrm{~W} / \mathrm{mK}$. Panel 5 can be considered advantageous with a composition of $58 \%$ of Cork, $21 \%$ of Rice Husk and $21 \%$ of Coffee Chaff: $0.066 \mathrm{~W} / \mathrm{mK}$ for thermal conductivity and $2.2 \mathrm{~kg} \mathrm{CO} 2 \mathrm{eq} / 1 \mathrm{~m}^{2}$ for the carbon footprint analysis. This is the best solution together with the best mixture found in panel 1 (minimum $\lambda$ and GWP). Finally, the best mixing for panel 6 is $30 \%$ of Cork, $23 \%$ of RH, $23 \%$ of CC, and $23 \%$ of ELT, respectively.

For the sake of clarity, the data with the best solution identified by this analysis are summarized in Table 8. The same analysis could be carried out also in terms of Embodied Energy for the construction of $1 \mathrm{~m}^{2}$ of panel.

The results are very similar and the data about the identified best mixtures are shown in Table 9: for panel 1 the best behavior is obtained with $43 \%$ of cork (instead of $37 \%$ for GWP), with about the same $\lambda(0.062 \mathrm{~W} / \mathrm{mK})$. For panel 2 a mixture of $50 \%$ of cork and $50 \%$ of CC is a good compromise. As in the first analysis panel 3 is not suitable; whereas, for panel 4 a percentage of COR equal to about 30\% allows minimum $\lambda$ and CED values, as observed above. Nothing changes also for the analysis of panel 5, that has the best mixture for $58 \%$ of Cork, $21 \%$ of Rice Husk and $21 \%$ of Coffee Chaff. Finally, for panel 6 the best solution is the one that has been investigated $(40 \%$ of COR, $20 \%$ of RH, $20 \%$ of CC, and $20 \%$ of ELT), with $\lambda$ of $0.071 \mathrm{~W} / \mathrm{mK}$ and CED of about $43 \mathrm{MJ} / \mathrm{m}^{2}$. 


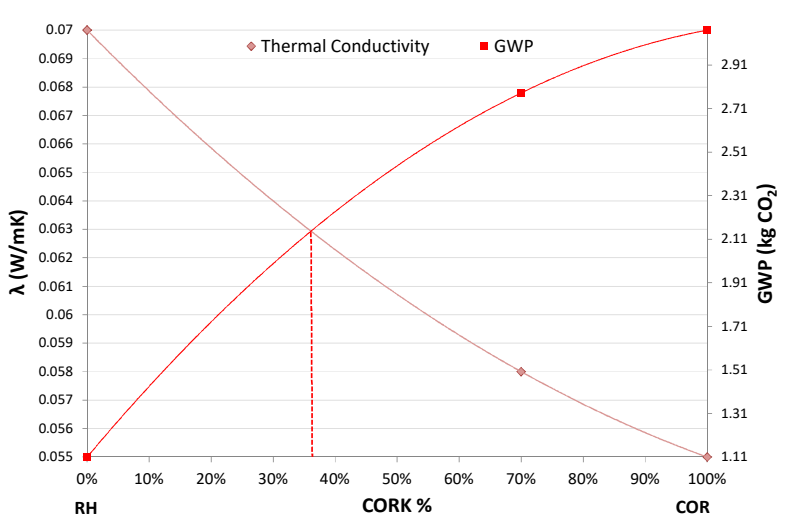

(a)

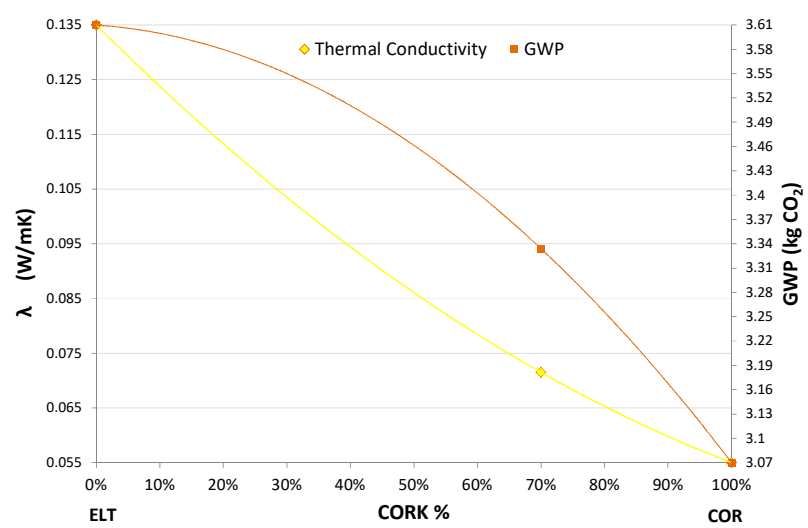

(c)

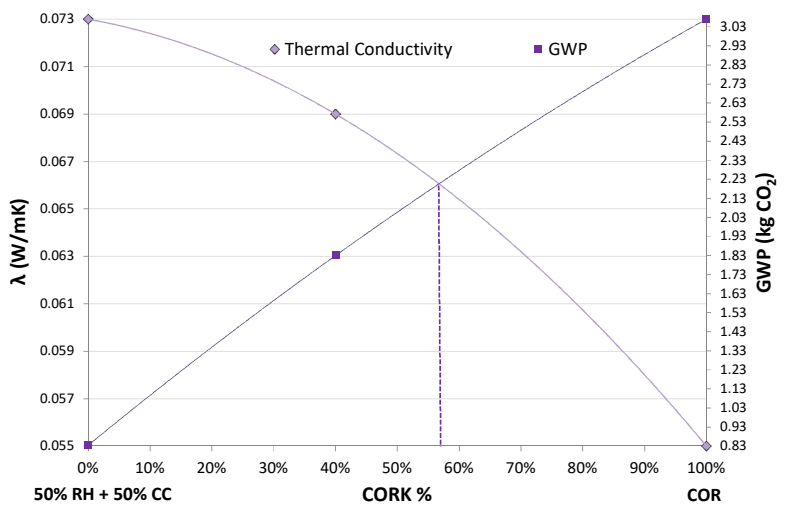

(e)

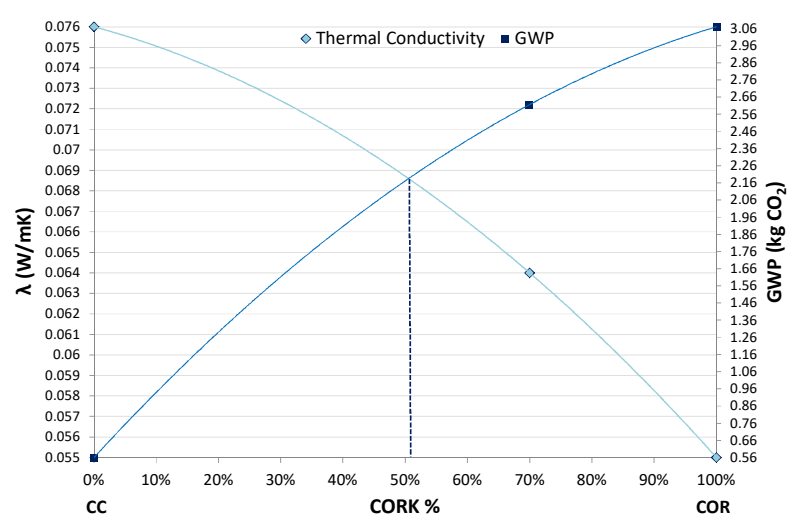

(b)

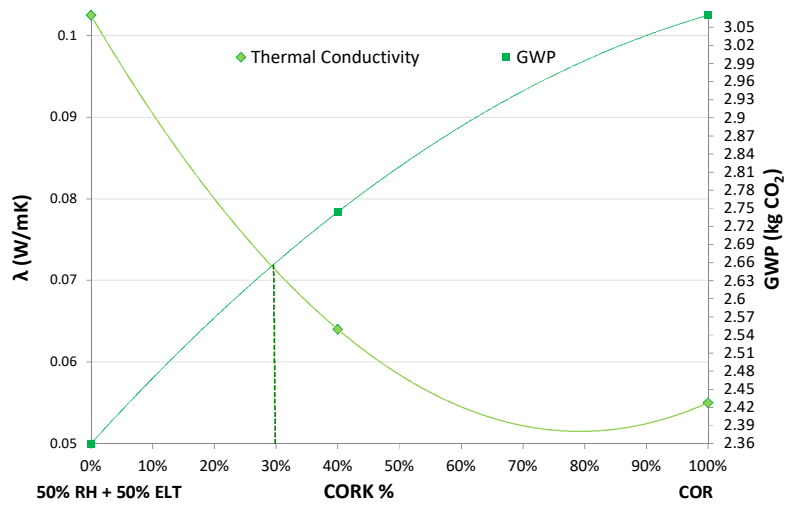

(d)

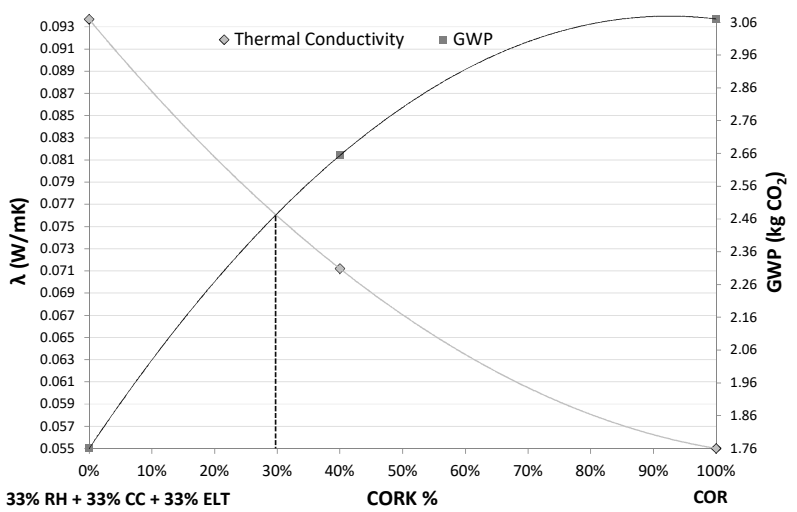

(f)

Figure 4. Cross-comparative analysis of the panels in terms of thermal conductivity and GWP for $1 \mathrm{~m}^{2}$ of panel: (a) panel 1 ; (b) panel 2; (c) panel 3; (d) panel 4; (e) panel 5; (f) panel 6. 
Table 8. Global Warming Potential and Thermal Conductivity values obtained for the best identified mixture (in the grey column the best mixing ratios are reported).

\begin{tabular}{|c|c|c|c|c|c|c|}
\hline & $\begin{array}{c}\mathrm{GWP} \\
\left(\mathrm{kg} \mathrm{CO}_{2 \mathrm{eq}}\right)\end{array}$ & $\lambda(\mathrm{W} / \mathrm{mK})$ & $\begin{array}{c}\text { GWP } \\
\left(\mathrm{kg} \mathrm{CO}_{2 \mathrm{eq}}\right)\end{array}$ & $\lambda(\mathrm{W} / \mathrm{mK})$ & $\begin{array}{c}\mathrm{GWP} \\
\left(\mathrm{kg} \mathrm{CO}_{2 \mathrm{eq}}\right)\end{array}$ & $\lambda(\mathrm{W} / \mathrm{mK})$ \\
\hline \multirow{2}{*}{1} & \multicolumn{2}{|c|}{$100 \% \mathrm{RH}$} & \multicolumn{2}{|c|}{$37 \% \mathrm{COR}+63 \% \mathrm{RH}$} & \multicolumn{2}{|c|}{$100 \%$ COR } \\
\hline & 1.11 & 0.07 & 2.17 & 1.11 & 0.07 & 0.055 \\
\hline \multirow{2}{*}{2} & \multicolumn{2}{|c|}{$100 \%$ CC } & \multicolumn{2}{|c|}{$51 \% \mathrm{COR}+49 \% \mathrm{CC}$} & \multicolumn{2}{|c|}{$100 \%$ COR } \\
\hline & 0.56 & 0.076 & 2.16 & 0.56 & 0.076 & 0.055 \\
\hline \multirow{2}{*}{3} & \multicolumn{2}{|c|}{$100 \%$ ELT } & \multicolumn{2}{|c|}{$100 \%$ COR } & \multicolumn{2}{|c|}{-} \\
\hline & 3.61 & 0.135 & 3.07 & 3.61 & 0.135 & \\
\hline \multirow[b]{2}{*}{4} & \multicolumn{2}{|c|}{$50 \% \mathrm{RH}+50 \% \mathrm{ELT}$} & \multicolumn{2}{|c|}{$30 \% \mathrm{COR}+35 \% \mathrm{ELT}+35 \% \mathrm{RH}$} & \multicolumn{2}{|c|}{$100 \%$ COR } \\
\hline & 2.36 & 0.102 & 2.65 & 2.36 & 0.102 & 0.055 \\
\hline \multirow[b]{2}{*}{5} & \multicolumn{2}{|c|}{$50 \% \mathrm{RH}+50 \% \mathrm{CC}$} & \multicolumn{2}{|c|}{$58 \% \mathrm{COR}+21 \% \mathrm{RH}+21 \% \mathrm{CC}$} & \multicolumn{2}{|c|}{$100 \%$ COR } \\
\hline & 0.83 & 0.073 & 2.18 & 0.83 & 0.073 & 0.055 \\
\hline \multirow[b]{2}{*}{6} & $33 \% \mathrm{RH}+3$ & $+33 \%$ ELT & \multicolumn{2}{|c|}{$30 \% \mathrm{COR}+23 \% \mathrm{RH}+23 \% \mathrm{CC}+23 \%$ ELT } & \multicolumn{2}{|c|}{$100 \%$ COR } \\
\hline & 1.76 & 0.094 & 2.46 & 1.76 & 0.094 & 0.055 \\
\hline
\end{tabular}

Table 9. Cumulative Energy Demand and Thermal conductivity values obtained for the best identified mixture (in the grey column the best mixing ratios are reported).

\begin{tabular}{|c|c|c|c|c|c|c|}
\hline & $\begin{array}{c}\text { CED } \\
\left(\mathrm{MJ} / 1 \mathrm{~m}^{2}\right)\end{array}$ & $\lambda(\mathrm{W} / \mathrm{mK})$ & $\begin{array}{c}\text { CED } \\
\left(\mathrm{MJ} / 1 \mathrm{~m}^{2}\right)\end{array}$ & $\lambda(\mathrm{W} / \mathrm{mK})$ & $\begin{array}{c}\text { CED } \\
\left(\mathrm{MJ} / 1 \mathrm{~m}^{2}\right)\end{array}$ & $\lambda(\mathrm{W} / \mathrm{mK})$ \\
\hline \multirow[b]{2}{*}{1} & \multicolumn{2}{|c|}{$100 \% \mathrm{RH}$} & \multicolumn{2}{|c|}{$42 \% \mathrm{COR}+58 \% \mathrm{RH}$} & \multicolumn{2}{|c|}{$100 \%$ COR } \\
\hline & 22.13 & 0.07 & 39.50 & 0.0617 & 61.85 & 0.055 \\
\hline \multirow{2}{*}{2} & \multicolumn{2}{|c|}{$100 \%$ CC } & \multicolumn{2}{|c|}{$56 \% \mathrm{COR}+44 \% \mathrm{CC}$} & \multicolumn{2}{|c|}{$100 \%$ COR } \\
\hline & 1.47 & 0.076 & 37.10 & 0.067 & 61.85 & 0.055 \\
\hline \multirow{2}{*}{3} & \multicolumn{2}{|c|}{$100 \%$ ELT } & \multicolumn{2}{|c|}{$100 \%$ COR } & \multirow{2}{*}{\multicolumn{2}{|c|}{ - }} \\
\hline & 67.74 & 0.135 & 61.85 & 0.055 & & \\
\hline \multirow[b]{2}{*}{4} & \multicolumn{2}{|c|}{$50 \%$ RH $+50 \%$ ELT } & \multicolumn{2}{|c|}{$32 \%$ COR + 34\% RH + 34\% ELT } & \multicolumn{2}{|c|}{$100 \%$ COR } \\
\hline & 44.93 & 0.102 & 50.80 & 0.070 & 61.85 & 0.055 \\
\hline \multirow[b]{2}{*}{5} & \multicolumn{2}{|c|}{$50 \% \mathrm{RH}+50 \% \mathrm{CC}$} & \multicolumn{2}{|c|}{$58 \% \mathrm{COR}+21 \% \mathrm{RH}+21 \% \mathrm{CC}$} & \multicolumn{2}{|c|}{$100 \%$ COR } \\
\hline & 11.80 & 0.073 & 41.50 & 0.066 & 61.85 & 0.055 \\
\hline \multirow[b]{2}{*}{6} & $33 \% \mathrm{RH}+3$ & $+33 \%$ ELT & $40 \% \mathrm{COR}+20 \%$ & $\mathrm{CC}+20 \% \mathrm{ELT}$ & \multicolumn{2}{|c|}{$100 \%$ COR } \\
\hline & 30.45 & 0.094 & 43.5 & 0.071 & 61.85 & 0.055 \\
\hline
\end{tabular}

The presented analysis could be very useful for a careful optimization of the possible mixture of building components, such as insulating composed panels, taking into account different points of view.

\section{Conclusions}

With the help of efficient insulation systems for building, energy efficiency can be increased. In particular, natural insulation materials can be favorably used in buildings in combination with standard panels in order to propose sustainable solutions and healthy indoor environment. Not only natural scraps, but also waste components from industrial and cultivation processes can be successfully used to these aims. In this context, four kinds of recycled waste materials were used in order to compose insulation panels for building opaque envelope and their properties were analyzed in order to find the best solutions by considering both thermal behavior and environmental impact. These panels were fabricated with cold-water-based polyurethane glue by means of cold pressing. A cross-comparative analysis is the core part of the paper: it was carried out in order to select the best compromise solutions in terms of thermal and environmental analysis. It was observed that cork has the best thermal performance (lower thermal conductivity) and the panels with higher weight ratio of cork are the best ones. Nevertheless, it has a not very low environmental impact with respect to rice husk and coffee chaff. Therefore, the best sustainable solutions are the panels composed of $37 \%$ cork and $63 \%$ rice husk, $51 \%$ cork and $49 \%$ coffee chaff, or $58 \%$ cork, $21 \%$ rice husk, and $21 \%$ coffee chaff, being about the same the thermal conductivities $(0.063-0.068 \mathrm{~W} / \mathrm{mK})$ but showing the lower environmental impact. This kind of analysis has proven to be very effective for fixing of 
the best mixing composition of composed panels, also when considering other components in the future.

Author Contributions: All the authors contributed equally to the conception, the design, the experimental campaigns, the LCA analysis and the writing of this paper. All authors have read and agreed to the published version of the manuscript.

Funding: This research received no external funding.

Data Availability Statement: Further data presented in this study are available on request from the corresponding author. For the sake of brevity, some data are not publicly available.

Acknowledgments: The authors thank Luca Basso Ricci for his collaboration during the experimental campaigns.

Conflicts of Interest: The authors declare no conflict of interest.

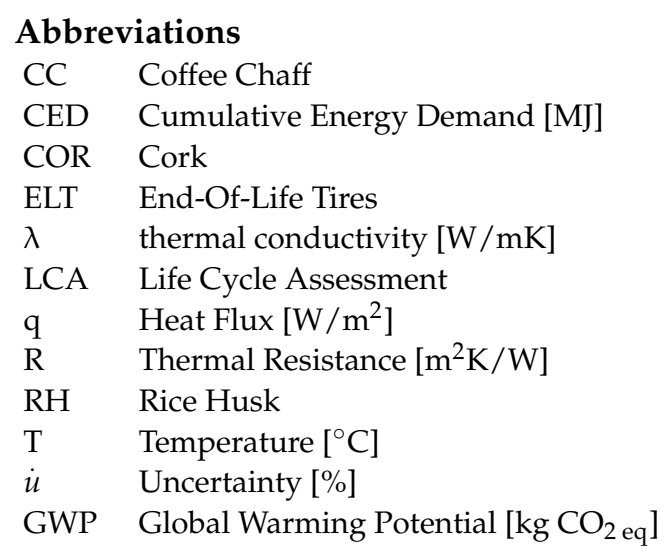

\section{References}

1. Perez-Lombard, L.; Ortiz, J.; Pout, C. A review on buildings energy consumption information. Energy Build. 2008, 40, 394-398. [CrossRef]

2. Directive, C. DIRECTIVE 2010/30/EU of the European Parliament and of the Council. Indication by labelling and standard product information of the consumption of energy and other resources by energy-related products. Off. J. Eur. Union 2010, $153,1-2$.

3. International Energy Agency. Key World Energy Statistics; International Energy Agency: Strasbourg, France, 2006.

4. Gaspar, F.; Bakatovich, A.; Davydenko, N.; Joshi, A. Building insulation materials based on agricultural wastes. In Bio-Based Materials and Biotechnologies for Eco-Efficient Construction; Woodhead Publishing Series in Civil and Structural Engineering; Woodhead Publishing: Duxford, UK, 2020; pp. 149-170.

5. Islam, S.; Bhat, G. Environmentally-friendly thermal and acoustic insulation materials from recycled textiles. J. Environ. Manag. 2019, 251, 109536. [CrossRef]

6. Ricciardi, P.; Belloni, E.; Cotana, F. Innovative panels with recycled materials: Thermal and acoustic performance and life cycle assessment. Appl. Energy 2014, 134, 150-162. [CrossRef]

7. Erkmen, J.; Yavuz, H.I.; Kavci, E.; Sari, M. A new environmentally friendly insulating material designed from natural materials. Constr. Build. Mater. 2020, 255, 119357. [CrossRef]

8. Volf, M.; Diviš, J.; Havlík, F. Thermal, moisture and biological behaviour of natural insulating materials. Energy Procedia 2015, 78, 1599-1604. [CrossRef]

9. Cornaro, C.; Zanella, V.; Robazza, P.; Belloni, E.; Buratti, C. An innovative straw bale wall package for sustainable buildings: Experimental characterization, energy and environmental performance assessment. Energy Build. 2020, 208, 109636. [CrossRef]

10. Mamo, S.; Skaar, C.; Gradeci, K.; Labonnote, N. Assessment of greenhouse gas emissions of ventilated timber wall constructions based on parametric LCA. J. Clean. Prod. 2018, 197, 34-46.

11. Yepes, V.; Martí, V.; Pons, J.J.; Penad, V. Life cycle assessment of earth-retaining walls: An environmental comparison. J. Clean. Prod. 2018, 192, 411-420.

12. Ricciardi, P.; Torchia, F.; Belloni, E.; Lascaro, E.; Buratti, C. Environmental characterisation of coffee chaff, a new recycled material for building applications. Constr. Build. Mater. 2017, 147, 185-193. [CrossRef]

13. Bakatovich, A.; Davydenko, N.; Gaspar, F. Thermal insulating plates produced on the basis of vegetable agricultural waste. Energy Build. 2018, 180, 72-82. [CrossRef] 
14. El-Naggar, K.A.M.; Amin, S.K.; El-Sherbiny, S.A.; Abadir, M.F. Preparation of geopolymer insulating bricks from waste raw materials. Constr. Build. Mater. 2019, 222, 699-705. [CrossRef]

15. Lu, J.; Zhou, Y.; He, P.; Wang, S.; Shen, P.; Poon, C.S. Sustainable reuse of waste glass and incinerated sewage sludge ash in insulating building products: Functional and durability assessment. J. Clean. Prod. 2019, 236, 117635. [CrossRef]

16. Buratti, C.; Belloni, E.; Lascaro, E.; Merli, F.; Ricciardi, P. Rice husk panels for building applications: Thermal, acoustic and environmental characterization and comparison with other innovative recycled waste materials. Constr. Build. Mater. 2018, 171, 338-349. [CrossRef]

17. Patnaik, A.; Mvubu, M.; Muniyasamy, S.; Botha, A.; Anandjiwala, R.D. Thermal and sound insulation materials from waste wool and recycled polyester fibers and their biodegradation studies. Energy Build. 2015, 92, 161-169. [CrossRef]

18. Ingrao, C.; Lo Giudice, A.; Tricase, C.; Rana, R.; Mbohwa, C.; Siracusa, V. Recycled PET fibre based panels for building thermal insulation: Environmental impact and improvement potential assessment for a greener production. Sci. Total Environ. 2014, 493, 914-929. [CrossRef]

19. Sormunen, P.; Kärki, T. Recycled construction and demolition waste as a possible source of materials for composite manufacturing. J. Build. Eng. 2019, 24, 100742. [CrossRef]

20. Buratti, C.; Belloni, E.; Merli, F. Water vapour permeability of innovative building materials from different waste. Mater. Lett. 2020, 265, 127459. [CrossRef]

21. Kumar, A.; Mohanta, K.; Kumar, D.; Parkash, O. Properties and Industrial Applications of Rice husk: A review. Int. J. Emerg. Tech. Adv. Eng. 2012, 2, 10.

22. Sarangi, M.; Bhattacharyya, S.; Behera, R.C. Rice Effect of temperature on morphology and phase transformations of nanocrystalline silica obtained from rice husk. Phase Transit. 2009, 82, 377-386. [CrossRef]

23. Buratti, C.; Belloni, E.; Lunghi, L.; Barbanera, M. Thermal Conductivity Measurements By Means of a New 'Small Hot-Box' Apparatus: Manufacturing, Calibration and Preliminary Experimental Tests on Different Materials. Int. J. Thermophys. 2016, 37, 47. [CrossRef]

24. EN ISO 8990. Thermal Insulation—Determination of Steadystate Thermal Transmission Properties—Calibrated and Guarded Hot Box European Standard; Comite Europeen de Normalisation: Bruxelles, Belgium, 1996.

25. JCGM 100. Evaluation of Measurement Data-Guide to the Expression of Uncertainty in Measurement; BIPM, Bureau International des Poids et Mesures: Sèvres, France, 2008.

26. JRC European Commission. ILCD Handbook: Recommendations for Life Cycle Impact Assessment in the European Context, Vasa; JRC European Commission: Ispra, Italy, 2011. [CrossRef]

27. ISO 14040. Environmental Management-Life Cycle Assessment-Principles and Framework, International Organization for Standardization; ISO, International Standard Organization: Geneva, Switzerland, 2006.

28. ISO 14044. Environmental Management-Life Cycle Assessment-Requirements and Guidelines; ISO, International Standard Organization: Geneva, Switzerland, 2006.

29. Lammel, G.; Grassl, H. Greenhouse effect of NOX. Environ. Sci. Pollut. Res. 1995, 2, 40-45. [CrossRef]

30. SimaPro Software. Available online: https://simapro.com/databases / (accessed on 15 June 2020).

31. Functional Unit. Available online: https://www.construction-products.eu/ (accessed on 18 July 2020). 